Article

\title{
Correlation between Antioxidant Activities and Phenolic Contents of Radix Angelicae Sinensis (Danggui)
}

\section{Xican Li *, Xiaoting Wu and Ling Huang}

School of Chinese Herbal Medicine, Guangzhou University of Chinese Medicine 510405, Guangzhou, China; E-Mails: idj811@hotmail.com (X.W.); hlkok26@foxmail.com (L.H.)

* Author to whom correspondence should be addressed; E-Mail: lixican@126.com; Tel.: +86 20 39358076; Fax: +86 2082246262 .

Received: 30 October 2009; in revised form: 4 December 2009 / Accepted: 14 December 2009 / Published: 21 December 2009

\begin{abstract}
Radix Angelicae Sinensisis (RAS) is one of the most popular traditional Chinese herbal medicines. In the present study, six RAS extracts (i.e., phenolic extract PE, petroleum ether extract PEE, ethyl acetate extract EAE, absolute ethanol extract AEE, 95\% ethanol extract $95 \mathrm{EE}$, and water extract WE) were prepared and their antioxidant activities measured by DPPH (1,1-diphenyl-2-picrylhydrazyl radical), ABTS [2,2'-azino-bis(3ethylbenzothiazoline-6-sulfonic acid diammonium salt)], Reducing power, $\cdot \mathrm{O}^{2-}$ and lipid peroxidation assays. In general, PE, PEE and EAE had relatively high antioxidant activity, followed by AEE with moderate activity, as compared with $95 \mathrm{EE}$ and WE that had low activity. Their phenolic contents (including total phenolic, ferulic acid, caffeic acid, same as below) were then determined by HPLC or spectrophotometry. The sequence of phenolic contents was roughly identical with that of antioxidant activity. When the values of $1 / \mathrm{IC}_{50}$ of various antioxidant assays were used to evaluate the level of antioxidant of the RAS extracts, (plot between $1 / \mathrm{IC}_{50}$ values and phenolic contents), the correlation coefficient (R) ranged from 0.642 to 0.941 , with an average value of 0.839 . Significant positive correlations demonstrated that the antioxidant effects of RAS might generally be considered a result of the presence of the phenolic compounds, especially ferulic acid and caffeic acid.
\end{abstract}

Keywords: Radix Angelicae Sinensis; antioxidant; phenolic; correlation 


\section{Introduction}

Radix Angelicae Sinensisis (RAS, named Danggui in Chinese) is the dried root of Angelica sinensis (Oliv.) Diels. As a Chinese herbal medicine, RAS was originally described in an ancient Traditional Chinese Medicine (TCM) classic named Shennong's Classic of Herbology, in which it is classified as top grade (superior). In TCM, it is mainly used to nourish blood, regulate menstruation, promote blood circulation, relieve pain and constipation [1]. As for the menstrual cycle and treatment of menopausal symptoms caused by the hormonal changes, it can produce favorable effects, so it is also known as "female ginseng" in Europe. Even though it is good for women, it also helps to treat the heart, spleen, liver and kidneys of both men and women. RAS, together with other Chinese herbal medicines can be used for treating various diseases, such as anemia [2], hepatitis [3], ulcerative colitis [4], dermatosis [5], neuropathy [6], cancer [7], diabetes and nephroses [8].

It has been well established that, a number of biochemical reactions involve the generation of reactive oxygen species (ROS) in our body. Under normal conditions, the balance between the generation and diminution of ROS is controlled by the antioxidant defense system, but under certain pathological conditions, when ROS are not effectively eliminated by the antioxidant defense system, the dynamic balance between the generation and diminution of ROS is broken. Excessive ROS attack lipids, carbohydrates, proteins, DNA, and result in oxidative stress, that leads to various disorders and diseases [9]. There are several studies which reported the antioxidant properties of RAS [10-12]. The purpose of this work was therefore to systematically assess the antioxidant activity and its correlation with the phenolic compounds found in RSA.

\section{Results and discussion}

\section{1. $\mathrm{DPPH} \cdot$ and $\mathrm{ABTS} \cdot{ }^{+}$scavenging activity}

The DPPH (1,1-Diphenyl-2-picrylhydrazyl radical) and ABTS [2,2'-azino-bis(3-ethylbenzothiazoline-6-sulfonic acid diammonium salt)] assays have been widely used to determine the free radical-scavenging activity of various plants and pure compounds. Both DPPH and ABTS are stable free radicals which dissolve in methanol or ethanol, and their colors show characteristic absorptions at $519 \mathrm{~nm}$ or $734 \mathrm{~nm}$, respectively. When an antioxidant scavenges the free radicals by hydrogen donation, the colors in the DPPH and ABTS assay solutions become lighter. As presented in Figures $1 \mathrm{~A}$ and $\mathrm{B}$, both the DPPH and ABTS inhibition percentage values were dose dependent, whereby they increased in the range of the tested concentrations, for the RAS extracts and the positive control (Trolox). Both the DPPH and ABTS radicals inhibition decreased in the order Trolox $>$ PE $>$ EAE $>$ PEE $>\mathrm{AEE}>\mathrm{WE} \approx 95 \mathrm{EE}$. The $\mathrm{DPPH}$ and $\mathrm{ABTS} \mathrm{IC}_{50}$ values $\left(\mathrm{IC}_{50}\right.$ value is the concentration of the sample required to inhibit $50 \%$ of radical) of the RAS extracts and Trolox were calculated and are listed in Table 1. 
Figure 1. Effect of different concentration of extracts of Radix Angelicae Sinensis in free radical scavenging tests: (A) DPPH assay, (B)ABTS assay, (C) Reducing power assay,(D) Superoxide anion assay, (E) Lipid peroxidation assay.
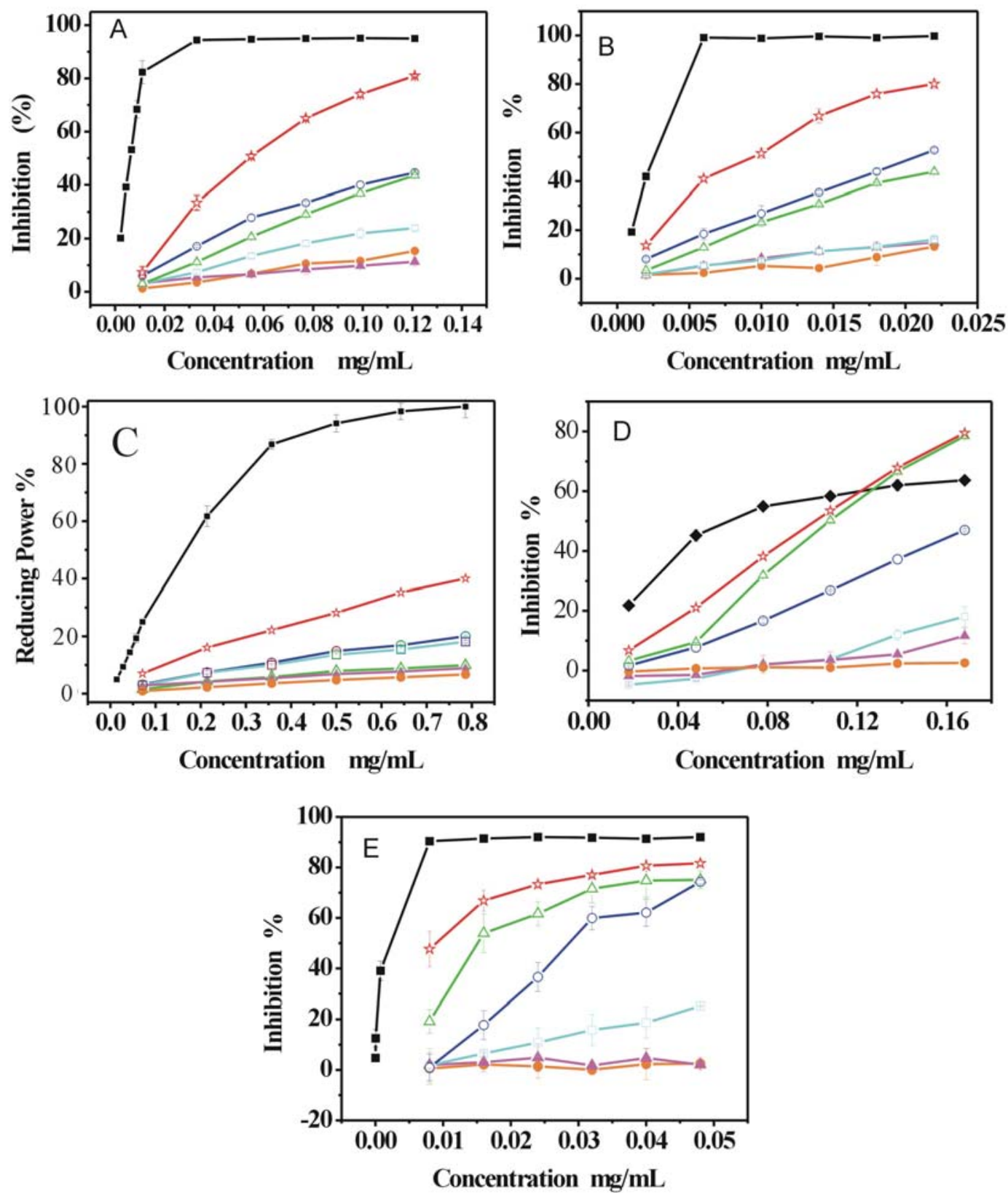

$\sum=\mathrm{PE}$ (phenolic extract); $\triangle=\mathrm{PEE}$ (petroleum ether extract); $\mathrm{O}=\mathrm{EAE}$ (ethyl acetate extract); $\square=\operatorname{AEE}$ (absolute ethanol extract); $\mathbf{\Delta}=95 \mathrm{EE}$ (95\% ethanol extract); $\bullet$ = WE (water extract);

- = Trolox (positive control ); $\bullet=$ GSH (positive control ); Each value is expressed as mean \pm standard deviation, $\mathrm{n}=3$. 
Table 1. The values of $\mathrm{IC}_{50}$ and $1 / \mathrm{IC}_{50}$ of the extracts of Radix Angelicae Sinensis.

\begin{tabular}{lcccccccccc}
\hline & \multicolumn{2}{c}{ DPPH } & \multicolumn{2}{c}{ ABTS } & \multicolumn{3}{c}{ Reducing power } & \multicolumn{2}{c}{$\boldsymbol{\bullet O}_{2}^{-}$} & \multicolumn{2}{c}{ LPO } \\
\cline { 2 - 12 } & $\mathrm{IC}_{50}$ & $1 / \mathrm{IC}_{50}$ & $\mathrm{IC}_{50}$ & $1 / \mathrm{IC}_{50}$ & $\mathrm{IC}_{50}$ & $1 / \mathrm{IC}_{50}$ & $\mathrm{IC}_{50}$ & $1 / \mathrm{IC}_{50}$ & $\mathrm{IC}_{50}$ & $1 / \mathrm{IC}_{50}$ \\
PE & 0.055 & 18.18 & 0.008 & 125 & 1.00 & 1.00 & 0.10 & 10 & 0.0083 & 120.48 \\
PEE & 0.14 & 7.14 & 0.023 & 43.48 & 3.87 & 0.26 & 0.11 & 9.09 & 0.015 & 66.67 \\
$\mathrm{EAE}$ & 0.13 & 7.69 & 0.022 & 45.45 & 2.03 & 0.49 & 0.18 & 5.56 & 0.028 & 35.71 \\
$\mathrm{AEE}$ & 0.24 & 4.17 & 0.070 & 14.29 & 2.38 & 0.42 & 0.39 & 2.56 & 0.093 & 10.75 \\
$95 \mathrm{EE}$ & 0.66 & 1.51 & 0.15 & 6.67 & 5.78 & 0.17 & 0.64 & 1.56 & 0.28 & 3.57 \\
WE & 0.39 & 2.56 & 0.093 & 10.75 & 5.62 & 0.18 & 2.77 & 0.36 & 1.00 & 1.00 \\
Control & $0.0061^{*}$ & $163.93^{*}$ & $0.0025^{*}$ & $400^{*}$ & $0.017^{*}$ & $58.82^{*}$ & $0.061^{* *}$ & $16.39^{* *}$ & $0.0025^{*}$ & $400^{*}$ \\
\hline
\end{tabular}

$\mathrm{PE}=$ phenolic extract; $\mathrm{PEE}=$ petroleum ether extract; $\mathrm{EAE}=$ ethyl acetate extract; $\mathrm{AEE}=$ absolute ethanol extract; $95 \mathrm{EE}=95 \%$ ethanol extract; $\mathrm{WE}=$ water extract; * Trolox; ** GSH.

\subsection{Reducing power assay}

The reducing power of an extract may serve as a significant indicator of its potential antioxidant activity. It can be seen that the reducing power percentage values of all RAS extracts and the positive control (Trolox) were concentration related and increased with the increase in sample concentration in the range of the tested concentrations (Figure 1C). Their relative reducing powers were as follows: Trolox $>$ PE $>$ EAE $>$ AEE $>$ PEE $>$ 95EE $>$ WE. The $\mathrm{IC}_{50}$ values of the RAS extracts and Trolox were calculated and are listed in Table 1.

\subsection{Superoxide anion $\left(\cdot \mathrm{O}_{2}-\right)$ radical-scavenging activity}

The superoxide radical was generated by the pyrogallol system at $\mathrm{pH}$ 8.2. Figure 1D shows the superoxide radical activity of the RAS extracts compared with the positive control (GSH). The positive control (GSH) and all RAS extracts demonstrated an ability to inhibit superoxide anion in a dose-dependent manner. At low concentrations $(0.00-0.12 \mathrm{mg} / \mathrm{mL})$, GSH had the highest inhibition percentage value, but it was exceeded by PE and PEE at high concentration $(>0.12 \mathrm{mg} / \mathrm{mL})$. According to the $\mathrm{IC}_{50}$ values (Table 1), the superoxide radical-scavenging activity of all samples decreased in the following order: $\mathrm{GSH}>\mathrm{PE}>\mathrm{PEE}>\mathrm{EAE}>\mathrm{AEE}>95 \mathrm{EE}>\mathrm{WE}$.

\subsection{Lipid peroxidation in a linoleic acid emulsion model system}

Lipid peroxidation (LPO) was used because of the formation of cytotoxic products such as MDA and 4-hydroxynonenal, which can influence cell function and the course of major human diseases [13]. As shown in Figure 1E, except for AEE, $95 \mathrm{EE}$ and WE, the other extracts and Trolox showed a good inhibitory activity against lipid peroxidation. Obviously, the activity of all samples occurred in the order Trolox $>\mathrm{PE}>\mathrm{PEE}>\mathrm{EAE}>\mathrm{AEE}>95 \mathrm{EE}>\mathrm{WE}$. The $\mathrm{LPO} \mathrm{IC}_{50}$ values were calculated and are listed in Table 1. 


\subsection{Total phenolic content}

The total phenolic contents of RAS extracts were determined and are presented in Table 2. The phenolic contents were calculated using pyrogallol. Analysis of the phenolic content in all of the extracts using the Folin-Ciocalteu method revealed that PE contained the maximum phenolic content $(30.20 \pm 0.18 \mathrm{mg} / \mathrm{g})$ in terms of pyragallol equivalents (PYR.), followed by EAE $(29.57 \pm 0.37 \mathrm{mg} / \mathrm{g})$, PEE $(28.83 \pm 0.64 \mathrm{mg} / \mathrm{g}), \operatorname{AEE}(15.65 \pm 0.68 \mathrm{mg} / \mathrm{g}), 95 \mathrm{EE}(5.310 .69 \mathrm{mg} / \mathrm{g})$, and WE(2.26 $\pm 0.55 \mathrm{mg} / \mathrm{g})$.

Table 2. The phenolic contents (including total phenolic,ferulic acid, caffeic acid) of the RAS extracts.

\begin{tabular}{|c|cccc|}
\cline { 2 - 5 } \multicolumn{1}{c|}{} & $\begin{array}{c}\text { Phenolic* } \\
\mathrm{mg} \mathrm{PYR} / \mathrm{g}\end{array}$ & $\begin{array}{c}\text { Ferulic acid* } \\
\mu \mathrm{g} / \mathrm{g}\end{array}$ & $\begin{array}{c}\text { Caffeic acid* } \\
\mu \mathrm{g} / \mathrm{g}\end{array}$ & $\begin{array}{c}\text { Ferulic acid plus Caffeic acid } \\
\mu \mathrm{g} / \mathrm{g}\end{array}$ \\
\hline $\mathrm{PE}$ & $30.20 \pm 0.18$ & $510.00 \pm 7.00$ & $160.00 \pm 2.30$ & 670.00 \\
$\mathrm{PEE}$ & $28.83 \pm 0.64$ & $6.40 \pm 0.14$ & $8.00 \pm 0.20$ & 14.00 \\
$\mathrm{EAE}$ & $29.57 \pm 0.37$ & $41.00 \pm 1.70$ & $4.60 \pm 0.12$ & 46.00 \\
$\mathrm{AEE}$ & $15.65 \pm 0.68$ & $5.20 \pm 0.18$ & $5.90 \pm 0.31$ & 11.00 \\
$95 \mathrm{EE}$ & $5.31 \pm 0.69$ & $8.80 \pm 0.74$ & 0.00 & 8.80 \\
$\mathrm{WE}$ & $2.26 \pm 0.55$ & $0.81 \pm 0.013$ & $1.00 \pm 0.11$ & 1.80 \\
\hline
\end{tabular}

* Each value is expressed as mean \pm standard deviation, $\mathrm{n}=3$.

\subsection{Determination of ferulic acid and caffeic acid by HPLC}

As the common active phenolic acid compounds, ferulic acid and caffeic acid had been earlier found in RAS and their antioxidant effects have also been reported in previous studies [14,15]. In the present study, the RAS extracts were assayed by chromatographic analysis, using the HPLC-UV, to determine the contents of ferulic acid and caffeic acid. Typical chromatograms of the standard compounds and EAE, WE are shown in Figure 2. The calibration curves of ferulic acid and caffeic acid also showed good linearity $(\mathrm{R}=0.9997$ and 0.9998 , respectively) (Table 3). As shown in Table 2, the results indicated that the ferulic acid content of PE $(510.00 \pm 7.00 \mu \mathrm{g} / \mathrm{g})$ was highest among the RAS extracts, followed by EAE $(41.00 \pm 1.70 \mu \mathrm{g} / \mathrm{g})$ as compared with $95 \mathrm{EE}(8.80 \pm 0.74 \mu \mathrm{g} / \mathrm{g})$, PEE $(6.40 \pm 0.14 \mu \mathrm{g} / \mathrm{g})$, AEE $(5.20 \pm 0.18 \mu \mathrm{g} / \mathrm{g})$ and $\mathrm{WE}(0.81 \pm 0.013 \mu \mathrm{g} / \mathrm{g})$, respectively. Moreover, PE also had the highest caffeic acid content $(160.00 \pm 2.30 \mu \mathrm{g} / \mathrm{g})$ on comparing it with PEE $(8.00 \pm 0.20 \mu \mathrm{g} / \mathrm{g}), \operatorname{AEE}(5.90 \pm 0.31 \mu \mathrm{g} / \mathrm{g}), \operatorname{EAE}(4.60 \pm 0.12 \mu \mathrm{g} / \mathrm{g}), \mathrm{WE}(1.00 \pm 0.11 \mu \mathrm{g} / \mathrm{g})$ and $95 \mathrm{EE}$, which showed complete absence of caffeic acid.

Table 3. The calibration curve and R values of caffeic acid and ferulic acid.

\begin{tabular}{ccc}
\hline Standard & Regression equation & $\mathrm{R}$ \\
\hline Ferulic acid & $y=645622568 x-223872$ & 0.9997 \\
Caffeic acid & $y=294445216 x-1399648$ & 0.9998 \\
\hline
\end{tabular}

Each value is expressed as mean \pm standard deviation, $n=3$. 
Figure 2. HPLC chromatograms of: (A) caffeic acid and ferulic acid (the standards), (B) ethyl acetate extract (EAE) and (C) water extract (WE).
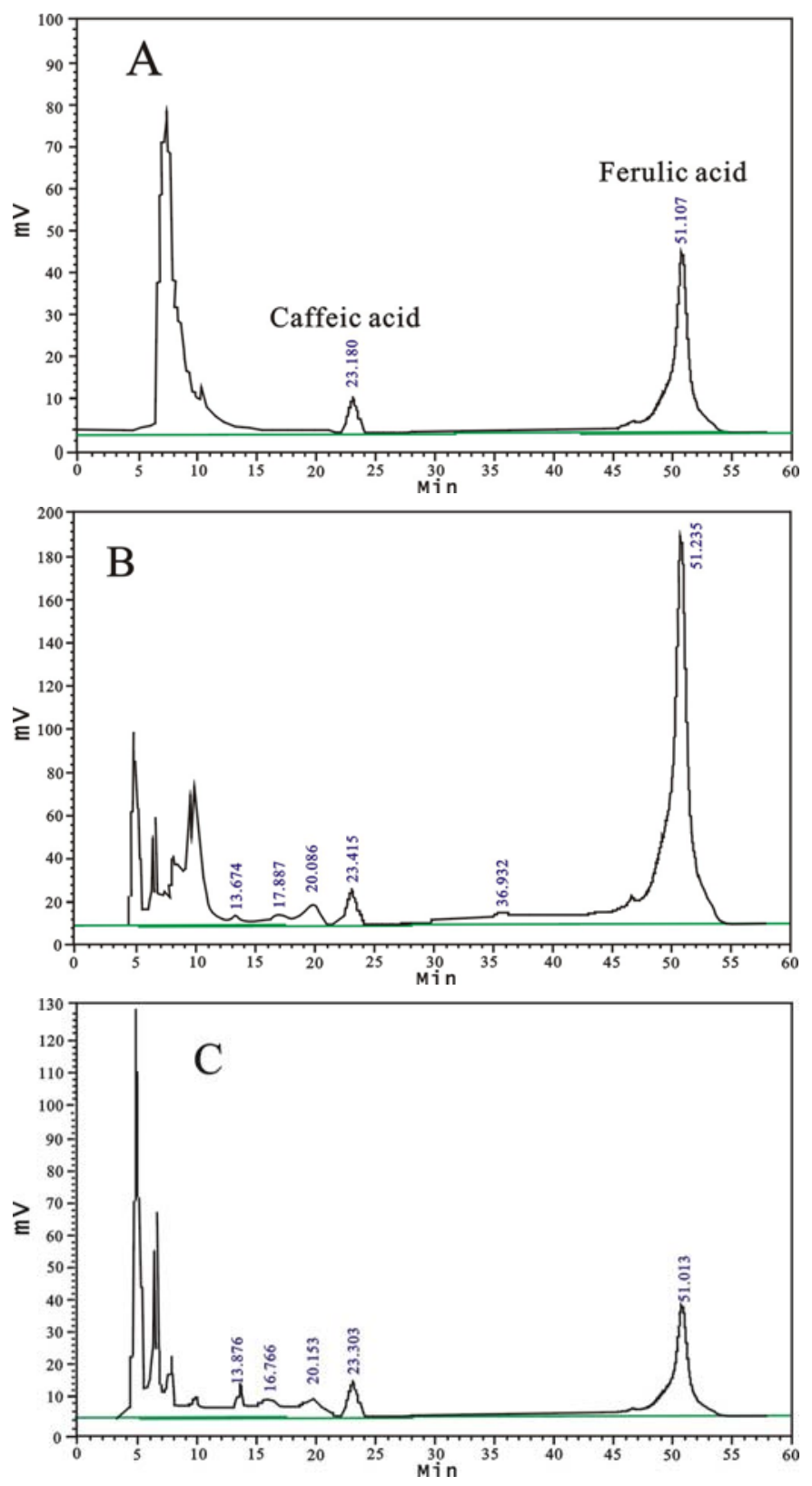

\section{Experimental}

\subsection{Plants material}

Radix Angelicae Sinensis was purchased from the Yanghe Pharmacy of Guangzhou University of Chinese Medicine (Guangzhou, China), and authenticated by Professor Shuhui Tan. A voucher specimen was deposited in our laboratory.

\subsection{Chemicals}

1,1-Diphenyl-2-picrylhydrazyl radical (DPPH·), pyrogallol, linoleic acid, Trolox [( \pm )-6hydroxyl-2,5,7,8-tetramethlychromane-2-carboxylic acid], Folin \& Ciocalteu's phenol reagent were 
purchased from Sigma Co. 2,2'-Azino-bis(3-ethylbenzothiazoline-6-sulfonic acid diammonium salt) (ABTS) and glutathione (GSH) were obtained from Amresco Co.; ferulic acid (NO.110773 -200611) and caffeic acid (NO.110885-200102) were obtained from NICPBP (National Institute for the Control of Pharmaceutical and Biological Products, China); acetonitrile and water were of HPLC grade. All other reagents were of analytical grade.

\subsection{Preparation of different extracts of Radix Angelicae Sinensis}

Radix Angelicae Sinensis (RAS) was ground to a coarse powder. Then the powdered sample was first extracted sequentially in the order of petroleum ether (b.p.60-90 ${ }^{\circ} \mathrm{C}$ ), ethyl acetate, absolute ethanol, 95\% ethanol, and water to obtain the petroleum ether extract (PEE), ethyl acetate extract (EAE), absolute ethanol extract (AEE), 95\% ethanol extract (95 EE), and water extract (WE), respectively (Figure 3). In addition, a phenolic extract (PE) of Radix Angelicae Sinensis was prepared using the $\mathrm{pH}$ adjustment method (Figure 4).

Figure 3. Extraction of Radix Angelicae Sinensis powder by increasing order solvent polarity.

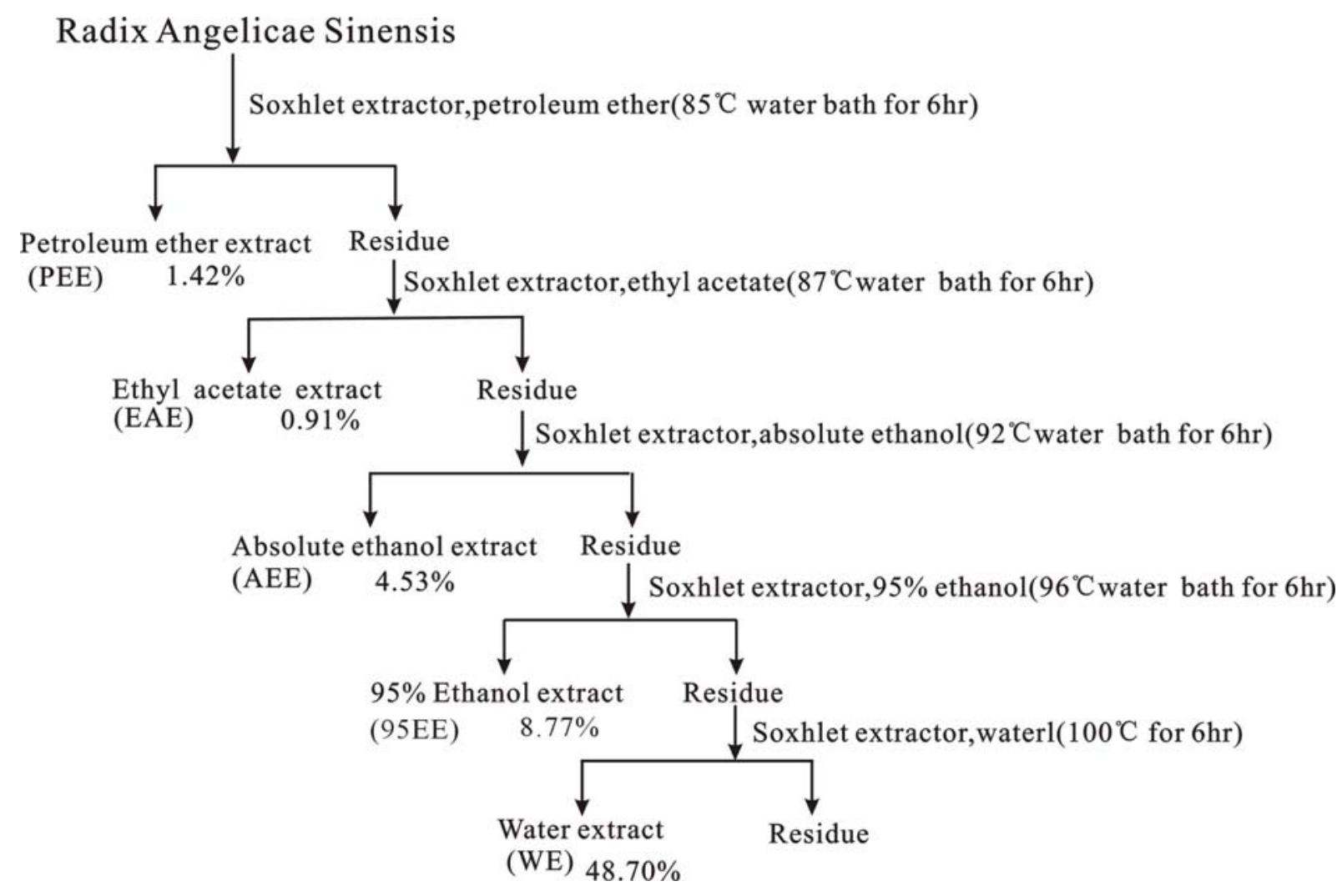


Figure 4. The preparation of phenolic extract (PE) of Radix Angelicae Sinensis using a pH adjustment method.

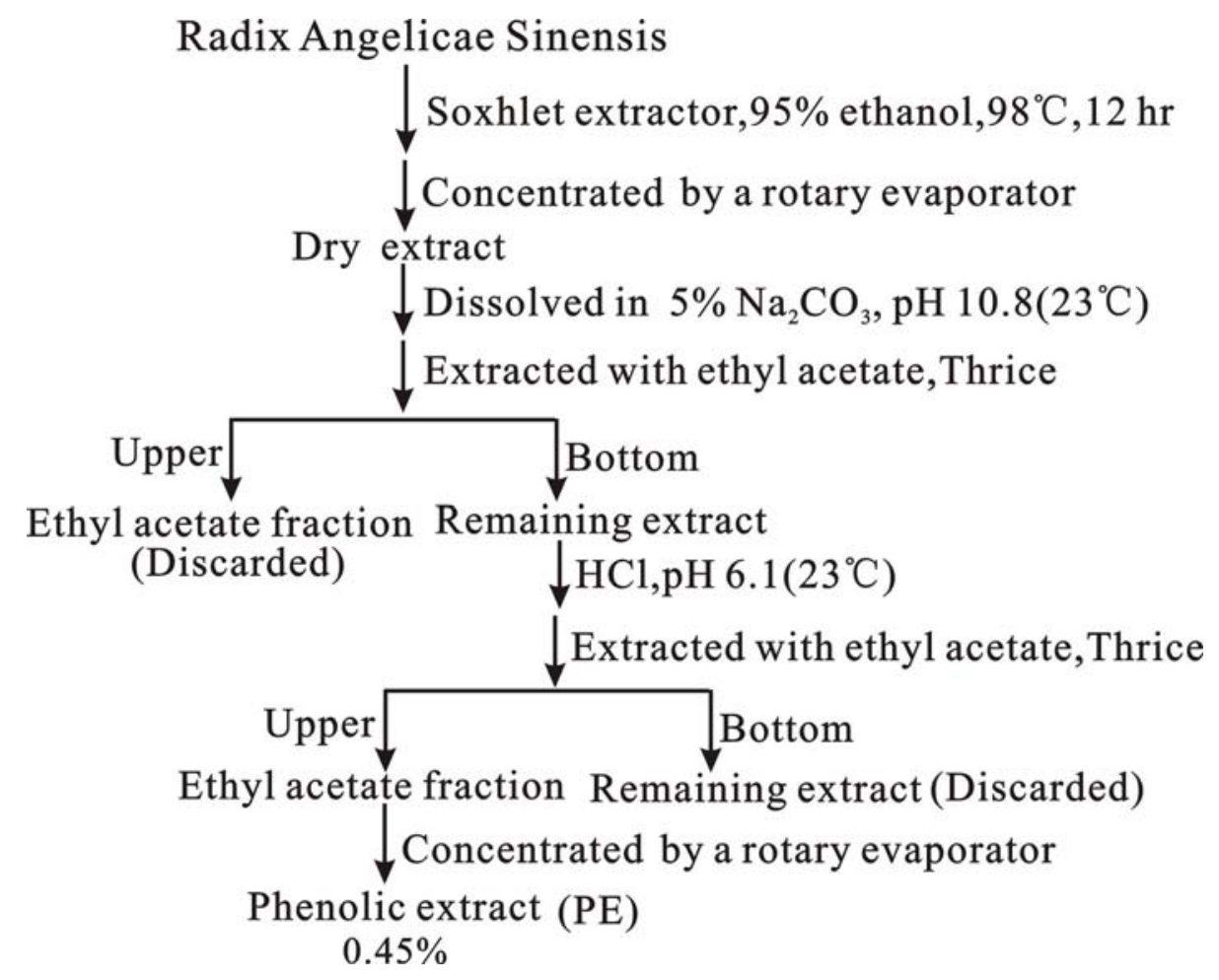

\subsection{DPPH radical-scavenging activity}

DPPH radical-scavenging activity was determined as described [16,17]. Briefly, DPPH·solution $(1 \mathrm{~mL}, 0.1 \mathrm{mmol} / \mathrm{L})$ was mixed with various concentrations of samples $(0.5 \mathrm{~mL})$ dissolved in suitable solvents (absolute or $95 \%$ ethanol). The mixture was kept at room temperature for $30 \mathrm{~min}$, and then the absorbance at $519 \mathrm{~nm}$ was measured on a spectrophotometer (UNICO 2100, Shanghai, China) using $95 \%$ ethanol as the blank. GSH was used as the positive control, and the percentage DPPH inhibition of the test samples was calculated as:

$$
\text { Inhibition } \%=\left(1-A / A_{0}\right) \times 100
$$

where $A_{0}$ is the absorbance at $519 \mathrm{~nm}$ of DPPH without sample, and $A$ is the absorbance at $519 \mathrm{~nm}$ of the reaction mixture containing DPPH and sample.

\subsection{ABTS $^{+}$radical cation scavenging activity}

The scavenging activity of $\mathrm{ABTS}^{+}{ }^{+}$was measured as described [18] with some modifications [19]. The ABTS $^{+}$was produced by mixing ABTS diammonium salt $(0.35 \mathrm{~mL}, 7.4 \mathrm{mmol} / \mathrm{L})$ with of potassium persulfate $(0.35 \mathrm{~mL}, 2.6 \mathrm{mmol} / \mathrm{L})$. The mixture was kept in the dark at room temperature for $12 \mathrm{~h}$ to allow completion of radical generation, and then diluted with $95 \%$ ethanol (about 1:50) so that its absorbance at $734 \mathrm{~nm}$ was $0.70 \pm 0.02$ measured on a spectrophotometer (UNICO 2100 Spectrophotometer; Shanghai, China). To determine the scavenging activity, ABTS ${ }^{+}$reagent $(1.2 \mathrm{~mL})$ was mixed with sample or negative control $(95 \%$ ethanol $)(0.3 \mathrm{~mL})$ and the absorbance at $734 \mathrm{~nm}$ was measured 6 min after the initial mixing, using 95\% ethanol as the blank. The percentage inhibition of 
the samples was calculated as:

$$
\text { Inhibition } \%=\left(1-A / A_{0}\right) \times 100
$$

where $A_{0}$ is the absorbance at $734 \mathrm{~nm}$ of the negative control, $A$ is the absorbance at $734 \mathrm{~nm}$ of the mixture with sample. Trolox, with a final concentration range of $0.002-0.022 \mathrm{mg} / \mathrm{mL}$, was prepared as a standard.

\subsection{Reducing power assay}

Reducing power was determined by the method of Oyaizu [20]. Samples $(x \mathrm{~mL})$ of each extract at various concentrations were mixed with $\mathrm{Na}_{2} \mathrm{HPO}_{4} / \mathrm{KH}_{2} \mathrm{PO}_{4}$ buffer $(3.5-x \mathrm{~mL}, 0.2 \mathrm{~mol} / \mathrm{L}$, $\mathrm{pH}$ 6.6) and $\mathrm{K}_{3} \mathrm{Fe}(\mathrm{CN})_{6}(2.5 \mathrm{~mL}, 1 \mathrm{~g} / 100 \mathrm{~mL})$. The mixture was incubated at $50{ }^{\circ} \mathrm{C}$ for $20 \mathrm{~min}$, TCA $(2.5 \mathrm{~mL}$, $10 \mathrm{~g} / 100 \mathrm{~mL}$ ) was added, and the mixture was centrifuged at 2,500 $\mathrm{g}$ for $10 \mathrm{~min}$. The supernatant $(2.5 \mathrm{~mL})$ was recovered, mixed with distilled water $(2.5 \mathrm{~mL})$ and $\mathrm{FeCl}_{3}(2.5 \mathrm{~mL}, 0.1 \mathrm{~g} / 100 \mathrm{~mL})$ and placed immediately into the spectrophotometer (UNICO 2100, Shanghai, China), and the timer was started. The absorbance at $700 \mathrm{~nm}$ was measured at $90 \mathrm{~s}$. Samples were analyzed in groups of three, and when the analysis of one group has finished, the next group of three samples were mixed with $\mathrm{FeCl}_{3}$ to avoid oxidization by air. GSH was used as the positive control, and an increased absorbance reading indicated increased reducing power. The percentage reduction of the sample as compared to standard, i.e., GSH was calculated by using the formula $\left(1-A_{S} / A_{C}\right) \times 100$. Here, $A_{C}=$ absorbance of standard at maximum concentration tested and $A_{S}=$ absorbance of sample.

\subsection{Superoxide anion $\left(\cdot \mathrm{O}_{2}^{-}\right)$radical-scavenging activity for auto-oxidation of pyrogallol}

The scavenging ability at $\mathrm{pH} 8.2$ of all test samples was determined by the method of Marklund and Marklund [21], as described by Wang [22]. Briefly, samples were dissolved in suitable solvents (absolute or $95 \%$ ethanol) at a concentration of $2 \mathrm{mg} / \mathrm{mL}$. The sample solution $(x \mu \mathrm{L}$, where $x=0,25$, $50,100,150,200$, or $250 \mu \mathrm{L})$ was mixed with Tris-HCl buffer $(1475-x \mu \mathrm{L}, 0.05 \mathrm{~mol} / \mathrm{L}, \mathrm{pH} 8.2)$ containing EDTA $(1 \mathrm{mmol} / \mathrm{L})$ and pyrogallol $(25 \mu \mathrm{L}, 6 \mathrm{mmol} / \mathrm{L})$, then shaken rapidly at room temperature. The absorbance at $325 \mathrm{~nm}$ of the mixture was measured (UNICO 2100, Shanghai, China) against the Tris- $\mathrm{HCl}$ buffer every $30 \mathrm{~s}$ for $5 \mathrm{~min}$. The slope of the correlation of absorbance with time was calculated. The reaction mixture without added sample was used as the control. The $\cdot \mathrm{O}_{2}^{-}$ scavenging ability was calculated as:

$$
(1-\text { Slope of sample/Slope of control }) \times 100 \%
$$

\subsection{Lipid peroxidation in a linoleic acid emulsion model system}

Lipid peroxidation (LPO) in a linoleic acid emulsion model system was applied to produce peroxyl radical (LOO·). The scavenging ability of the RAS extracts on LPO was assessed by a method using ammonium thiocyanate [23,24]. A linoleic acid emulsion was made by vortexing a mixture of linoleic acid (312.6 mg) with Tween20 (78.2 mg) in 30\% (v/v) ethanol $(20 \mathrm{~mL})$. The reaction mixture consisted of linoleic acid emulsion $(1.5 \mathrm{~mL})$ and sample solution $(0.1 \mathrm{~mL})$. The total volume was adjusted to $2.0 \mathrm{~mL}$ with distilled water, and the reaction mixture was incubated at room temperature in an open vitreous bottle for $72 \mathrm{~h}$. Samples $(0.15 \mathrm{~mL})$ were withdrawn from the incubated mixture and 
tested for lipid peroxidation. The assay consisted of sequential addition of $75 \%(\mathrm{v} / \mathrm{v})$ ethanol $(3.65 \mathrm{~mL})$, ammonium thiocyanate $(0.1 \mathrm{~mL}, 30 \mathrm{~g} / 100 \mathrm{~mL})$, and ferrous sulfate $(0.1 \mathrm{~mL}, 0.02 \mathrm{~mol} / \mathrm{L}$ in $3.6 \%, \mathrm{v} / \mathrm{v}, \mathrm{HCl})$. After the mixture was rested for $3 \mathrm{~min}$, the color development was determined as the difference of absorbance at $500 \mathrm{~nm}$ against that of $75 \%$ ethanol in the reference cuvette (UNICO 2100 , Shanghai, China). The scavenging ability on LPO was calculated as:

$$
\text { Inhibition } \%=\left(1-A_{500 \mathrm{~nm}(\text { sample })} / A_{500 \mathrm{~nm}(\text { reference })}\right) \times 100
$$

\subsection{Determination of total phenolic content (TP)}

Total phenolic (TP) contents of the RAS extracts were analyzed by the Folin-Ciocalteu method [25]. In brief, samples of the extract were taken into a test-tube and made to a volume of $0.5 \mathrm{~mL}$ with $95 \%$ ethanol, the Folin-Ciocalteu reagent $(0.5 \mathrm{~mL}, 0.25 \mathrm{~mol} / \mathrm{L})$ and the $\mathrm{Na}_{2} \mathrm{CO}_{3}$ reagent $(1.0 \mathrm{~mL}, 150 \mathrm{~g} / \mathrm{L})$ were added, and the mixture was incubated at room temperature for $30 \mathrm{~min}$. The absorbance at $760 \mathrm{~nm}$ of the mixture was measured (UNICO 2100 spectrophotometer, Shanghai, China), and the amount of total phenol was calculated as pyrogallol equivalents (mg PYR/g) from the calibration curve.

\subsection{HPLC analysis for ferulic acid and caffeic acid}

HPLC analysis of the RAS extracts for ferulic acid, caffeic acid was carried out on a LC2000 system equipped with a UV detector (Techcomp Ltd., China) and a L-2200 autosampler (Hitachi, Japan). The column was a $\mathrm{C}_{18}$ reversed-phase column (Diamonsil $5 \mu \mathrm{m}$ film thickness, $250 \mathrm{~mm} \times 4.6 \mathrm{~mm}$, Dikma Ltd., China). The separation was performed isocratically with a mobile phase consisting of $0.1 \%(\mathrm{v} / \mathrm{v})$ water acetic acid and acetonitrile (83:17) . The injection volume was $50 \mu \mathrm{L}$. The flow rate was $0.5 \mathrm{~mL} / \mathrm{min}$ and detection was at $325 \mathrm{~nm}$ wavelength. The standard curves using ferulic acid $(0.01-0.08 \mathrm{mg} / \mathrm{mL})$ and caffeic acid $(0.07-0.112 \mathrm{mg} / \mathrm{mL})$ were constructed and quantifications were done on the basis of the standard curves of ferulic acid and caffeic acid, respectively.

\subsection{Statistical analysis}

Data are given as the mean $\pm \mathrm{SD}$ of three measurements. The $\mathrm{IC}_{50}$ values were calculated by linear regression analysis. All linear regression in this paper was analyzed by Origin 6.0 professional software.

\section{Conclusions}

Six extracts of Radix Angelicae Sinensisis dose-dependently increased the radical inhibition (or reducing power) values, suggesting that RAS possesses antioxidant activity. Therefore, RAS's various pharmacological activities and curative effects maybe closely correlated with its antioxidant activities. However, the antioxidant activities of six RAS extracts were different within the tested concentration ranges. In general, PE, PEE and EAE had relatively high antioxidant activity, followed by AEE with moderate activity, as compared with $95 \mathrm{EE}$ and WE which displayed low activity. This sequence of antioxidant activity was roughly identical to that of phenolic (including total phenolic, ferulic acid, caffeic acid) contents (Table 2). Thus, the antioxidant activity of RAS may likely be attributed to the 
phenolic content in each extract. This conclusion is expected, as similar observations have been reported in a large number of previous researches.

Furthermore, quantitative analysis was also used for investigating the correlation between antioxidant activities and phenolic contents in different extracts of RAS. As the $1 / \mathrm{IC}_{50}$ (not $\mathrm{IC}_{50}$ ) value showed parallelism with antioxidant activity, it was therefore calculated (Table 1) and used for evaluating antioxidant activity. In the present study, twenty correlation graphs were plotted between $1 / \mathrm{IC}_{50}$ values (including of $\mathrm{DPPH}, \mathrm{ABTS}$, reducing power, $\cdot \mathrm{O}_{2}^{-}$and $\mathrm{LPO}$ ) and phenolic contents (including total phenolic, ferulic acid, caffeic acid and ferulic acid plus caffeic acid). Two typical correlation graphs (i.e., DPPH vs total phenolic, DPPH vs ferulic acid) are shown in Figure 5, while Table 4 shows the correlation coefficient $(\mathrm{R})$ of the various assays and phenolic contents.

Figure 5. Correlation graphs for DPPH $1 / \mathrm{IC}_{50}$ values and (A) total phenolic contents , (B) ferulic acid contents in the six RAS extracts.
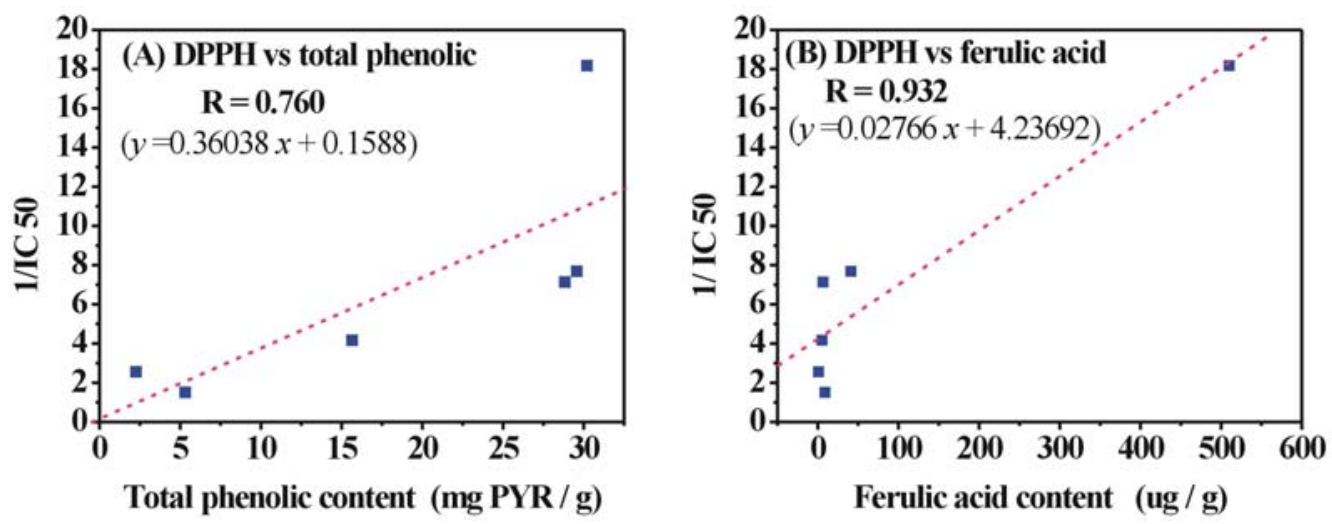

Table 4. The $\mathrm{R}$ values (correlation coefficients) between antioxidant activities $\left(1 / \mathrm{IC}_{50}\right)$ and phenolic contents.

\begin{tabular}{lcccccc} 
& $\mathrm{DPPH}$ & $\mathrm{ABTS}$ & Reducing power & . $_{2}^{-}$ & LPO & Average \\
\hline Total phenolic & 0.760 & 0.733 & 0.659 & 0.914 & 0.795 & $\mathbf{0 . 7 7 2}$ \\
Ferulic acid & 0.933 & 0.941 & 0.929 & 0.642 & 0.856 & $\mathbf{0 . 8 6 0}$ \\
Caffeic acid & 0.929 & 0.938 & 0.920 & 0.655 & 0.867 & $\mathbf{0 . 8 6 2}$ \\
Ferulic acid plus Caffeic acid & 0.931 & 0.941 & 0.928 & 0.645 & 0.859 & $\mathbf{0 . 8 6 1}$ \\
\multicolumn{1}{c}{ Average } & $\mathbf{0 . 8 8 8}$ & $\mathbf{0 . 8 8 8}$ & $\mathbf{0 . 8 5 9}$ & $\mathbf{0 . 7 1 4}$ & $\mathbf{0 . 8 4 4}$ & \\
\hline
\end{tabular}

As shown in Figure 5 and Table 4, significant positive correlations $(\mathrm{R}=0.659-0.911$, the average of $\mathrm{R}$ was 0.772 ) were observed between total phenolic content and $1 / \mathrm{IC}_{50}$ values for $\mathrm{DPPH}, \mathrm{ABTS}$, Reducing power, $\cdot \mathrm{O}_{2}{ }^{-}$and LPO assay, indicating the significant contribution of phenolics to these antioxidant assays. As the common phenolic acid compounds, ferulic acid (the average of $\mathrm{R}$ was 0.860 ) and caffeic acid (the average of $\mathrm{R}$ was 0.862 ) exhibit higher $\mathrm{R}$ values between antioxidant assays than total phenol (the average of $\mathrm{R}$ was 0.772 ). Therefore, it is indicated that ferulic acid and caffeic acid exert more antioxidant capacity than other phenolic compounds in the RAS extracts. In fact, ferulic acid has been reported to possess excellent inhibitory effect on $\bullet^{-}{ }_{2}^{-}, \cdot \mathrm{OH}$ and $\mathrm{NO}$ [26], and to serve an 
important antioxidant function in preserving physiological integrity of cells exposed to both air and impinging UV radiation[14]. Caffeic acid was also proved to be a more efficient antiradical compound than coumaric acid [17]

However, among the five antioxidant assays (i.e., DPPH, ABTS, reducing power, $\bullet \mathrm{O}_{2}{ }^{-}$and LPO), the the $\mathrm{R}$ value of the $\cdot \mathrm{O}_{2}{ }^{-}$assay appears abnormal to some extent. Ferulic acid ( $\mathrm{R} 0.642$ ) and caffeic acid ( $R$ 0.655) exhibit lower (not higher) $R$ values than total phenol ( $\mathrm{R} 0.914$ ). This result suggested that ferulic acid and caffeic acid exert less inhibitory effect on $\cdot \mathrm{O}_{2}{ }^{-}$than other phenolic compounds in the RAS extracts.

Nevertheless, twenty $R$ values ranged from 0.642 to 0.941 , and the average value was 0.839 , so these high levels suggest that the antioxidant activity of Radix Angelicae Sinensis might me in large part the result of the contributions of the phenolic compounds that it contained, especially ferulic acid and caffeic acid.

\section{References}

1. China Pharmacopoeia Committee. Pharmacopoeia of the People's Republic of China; China Chemical Industry Press: Beijing, China, 2005; p. 89.

2. Tong, Y.Q.; Hou, H.M. Progress in mechanism of Danggui Buxue Tang therapy for anaemia (in Chinese). Jiangxi J. TCM 2006, 2, 62-63.

3. You, A.L. Adds. Danggui Buxue Tang Therapy for Virus Hepatitis (in Chinese). Modern TCM. 1991, 6, 44.

4. Bai, L.P.; Liu, X.F. Thirty Cases of Danggui Buxue Tang therapy for ulcerative colitis (in Chinese). Shaanxi J. TCM 2004, 9, 796-797.

5. Liu, Q. The Clinical application of Danggui Sini Tang in department of dermatology (in Chinese). Shaanxi J. TCM 1990, 8, 361-363.

6. Yan, G.H.; Hou, Q.Z.; Guo, G.B. Observation on effect of Adds. Danggui Sini Tang therapy for peripheral neuropathy causing by diabetes on 30 patients (in Chinese). New J. TCM 2006, 7, 53-54.

7. Yang, K.Z.; Sun, X.F. Observation on recent effect of Danggui Huoxue Tang I combined with chemical therapy treat metaphase-late malignant tumor (in Chinese). J. Shandong Med. 2004, 7, 41-42.

8. Zhou, Y.L. Danggui Liuhuang Tang therapy for early diabetes and nephrosis on 33 patients (in Chinese). TCM Res. 2008, 5, 37-38.

9. Zhao, X.Y.; Sun, H.D.; Hou, A.J.; Zhao, Q.S.; Wei, T.T.; Xin, W.J. Antioxidant properties of two gallotannins isolated from the leaves of Pistacia weinmannifolia. BBA Gen. Subj. 2005, 1725, 103-110.

10. Huang, S.H.; Chen, C.C.; Lin, C.M.; Chiang, B.H. Antioxidant and flavor properties of Angelica sinensis extracts as affected by processing. J. Food Compos. Anal. 2008, 21, 402-409.

11. Li, S.Y.; Yu, Y.; Li, S.P. Identification of antioxidants in essential oil of radix angelicae sinensis using HPLC coupled with DAD-MS and ABTS-based assay. J. Agr. Food Chem. 2007, 55, 3358-3362. 
12. Yang, X.B.; Zhao, Y.; Zhou, Y.J.; Mao, J.L.; Zhao, P. Component and antioxidant properties of polysaccharide fractions isolated from Angelica sinensis (Oliv.) diels. Biol. Pharm. Bull. 2007, 30, 1884-1890.

13. Sevanian, A.; Ursini, F. Lipid peroxidation in membranes and lowdensity lipoproteins: Similarities and differences. Free Radical Biol. Med. 2000, 29, 306-311.

14. Gülçin, I. Antioxidant activity of caffeic acid (3,4-dihydroxycinnamic acid). Toxicology 2006, 217, 213-220.

15. Ernst, G. Antioxidant potential of ferulic acid. Free Radical Bio. Med. 1992, 13, 435-448.

16. Blois, M.S. Antioxidant determinations by the use of a stable free radical. Nature 1958, 26, 1199-1200.

17. Brand-Williams, W.; Cuvelier, M.E.; Berset, C. Use of a free radical method to evaluate antioxidant activity. LWT Food Sci.Technol. 1995, 28, 25-30.

18. Re, R.; Pellegrini, N.; Proteggente, A.; Pannala, A. Antioxidant activity applying an improved ABTS radical cation decolorization assay. Free Radical Bio. Med. 1999, 26, 1231-1237.

19. Thaipong, K.; Boonprakob, U.; Crosby, K. Comparison of ABTS, DPPH, FRAP and ORAC assays for estimating antioxidant activity from guava fruit extracts. J. Food Compos. Anal. 2006, 19, 669-675.

20. Oyaizu, M. Studies on product of browning reaction prepared from glucose amine. Jpn. J. Nutr. 1986, 44, 307-315.

21. Marklund, S.; Marklund, G. Involvement of the superoxide anion radical in the autoxidation of pyrogallol and convenient assay for superoxide dismutase. Eur. J. Biochem. 1974, 47, 469-474.

22. Wang, Z.J.; Luo, D. Antioxidant activities of different fractions of polysaccharide purified from Gynostemma pentaphyllum Makino. Carbohyd. Polym. 2007, 68, 54-58.

23. Siddhuraju, P. Antioxidant activity of polyphenolic compounds extracted from defatted raw and dry heated Tamarindus indica seed coat. LWT Food Sci.Technol 2007, 40, 982-990.

24. Kitts, D.D.; Arosha, N. W.; Chun, H. Antioxidant properties of a North American ginseng extract. Mol. Cell. Biochem. 2000, 203, 1-10.

25. Wua, S.J.; Ng, L.T. Antioxidant and free radical scavenging activities of wild bitter melon (Momordica charantia Linn. var. abbreviata Ser.) in Taiwan. LWT Food Sci.Technol 2008, 41, 323-330.

26. Ogiwara, T.; Satoh, K.; Kadoma, Y., Murakami, Y.; Unten, S.; Atsumi, T.; Sakagami, H.; Fujisawa, S. Radical scavenging activity and cytotoxicity of ferulic acid. Anticancer Res. 2002, 22, 2711-2717.

Sample Availability: Available from the authors.

C) 2009 by the authors; licensee Molecular Diversity Preservation International, Basel, Switzerland. This article is an open-access article distributed under the terms and conditions of the Creative Commons Attribution license (http://creativecommons.org/licenses/by/3.0/). 